\title{
Mononucleated Cells to Regenerate Skeletal Muscle Syncytial Tissues
}

\section{Gabriele Ceccarelli ${ }^{1}$, Flavio Ronzoni', Mattia Quattrocelli', Daniela Galli', Laura Benedetti ${ }^{1}$, Gabriella De Angelis Cusella ${ }^{1}$ and Maurilio} Sampaolesi ${ }^{1,2 *}$

${ }^{1}$ Human Anatomy Institute, Dept. of Public Health, Neuroscience, Experimental and Forensic Medicine, University of Pavia, Via Forlanini 8,27100 Pavia, Italy ${ }^{2}$ Laboratory of Translational Cardiomyology, SCIL, Dept. of Development and Regeneration, KULeuven University of Leuven, Herestraat 49 O and N4 bus 814,3000 Leuven, Belgium

\begin{abstract}
Skeletal muscle is one of the most plastic tissues of vertebrates since it may able upon exercises to double in size due to a physiological hypertrophy. Despite the fact that it is mainly a syncytial tissue, it contains a relevant number of mononucleated cells that can be involved in its homeostasis and repair. Although the mononuclear cell types with the highest myogenic potential are the satellite cells located underneath the basal lamina of muscle fibres, other interstitial cells have been shown to contribute to muscle regeneration.
\end{abstract}

Adding complexity to this scenario is the fact that several authors revealed myogenic potential in pluripotent stem cells, which can be generated from patient somatic cells and eventually manipulated to correct the genetic defect.

Notwithstanding the copiousness of myogenic cell types, their use in ex vivo cell therapies for muscular degenerative diseases is still questionable. However, new discovers on their biological properties have advanced our comprehension in handling myogenic stem cells significantly.

In this review, we will focus on the myogenic potential of multi- and pluri-potent stem cells and their use in preclinical and clinical studies. New insights from direct reprogramming and epigenetic signalling to generate myogenic stem cells are also considered.

Keywords: Stem cells; Skeletal muscle; Regenerative medicine

\section{Mimicking Human Muscle Pathology}

Muscular dystrophies (MDs) are a group of muscle diseases that affect the musculoskeletal system and locomotion [1-5]. MDs are characterized by defects in muscle proteins, determining progressive death of muscle cells and tissue [2,3]. There are several forms of MDs, including the Duchenne muscular dystrophy (DMD), the Becker muscular dystrophy (BMD) and some forms of limb-girdle muscular dystrophy (LGMD).

DMD is the most severe syndrome and it is caused by mutations in the dystrophin gene located on the human $\mathrm{X}$ chromosome, with an inheritance pattern of 3 cases per 10000 live male births [5-7]. Satellite cells are localized underneath the basal lamina of terminally differentiated muscle fibres and in response to injury, they proliferate, fuse and give rise to regenerated muscle. Unfortunately, genetic mutations responsible for DMD are also present in satellite cells. Hence, the ability to restore normal muscle function remains obstructed. In DMD patients a small number of muscle fibres are able to produce functional dystrophin, mostly due to secondary mutations in myogenic precursor cells, which restore the reading frame $[8,9]$. However, these so-called revertant fibres are in a too small minority to alleviate the pathology of the dystrophin-deficiency. Exhaustion of the satellite cell pool due to degeneration and regeneration cycles is thought to critically contribute to the disease $[10,11]$.

BMD is also caused by mutations in the dystrophin gene, but myofibrils retain a truncated and low-active form of the dystrophin protein, consequently the symptoms appear with a later, and much slower rate of progression [12,13]. Both BMD and DMD patients can show different degrees of cognitive damage, indicating that brain function is compromised. In the last stage of disease progression, the regenerative capacity of the muscles is lost, and muscle fibres are gradually replaced by adipose and fibrous connective tissue [1-13].
LGMD disease is a typically inherited disorder characterized by muscle weakness and cardiomyopathy, but in most case cognitive functions are not compromises. In LGMD, the function of several different proteins can be affected. LGMD can be autosomal dominant (LGMD1) or recessive (LGMD2). Among the proteins affected in the LGMD2 are $\gamma, \alpha, \beta$, and $\delta$ sarcoglycans responsible for LGMD type 2C, $2 \mathrm{D}, 2 \mathrm{E}$ and $2 \mathrm{~F}[14,15]$.

Several animal models have been developed during last 30 years to study muscular dystrophies, especially for DMD and LGMD. The $m d x$ mouse model presents a X-linked mutation in the dystrophin gene, mimicking the genotype of DMD patients [16-19]. In the last 10 years, the $m d x$ mice were extensively used for novel therapeutic approach studies. However, $m d x$ mice show a decline in muscle regenerative capacity only at advanced age ( $>65$ weeks), while necrotic processes persist with deposition of scar tissue. In addition, $m d x$ mice show a very efficient muscle regeneration and normal lifespan, in contrast to human DMD, where skeletal muscle is progressively damaged and replaced by fibrotic tissue and patients die prematurely $[19,20]$. Besides, a double mouse mutant lacking both dystrophin and utrophin

*Corresponding author: Maurilio Sampaolesi, PhD, Human Anatomy Institute, Dept. of Public Health, Neuroscience, Experimental and Forensic Medicine, Universityof Pavia, Via Forlanini 8, 27100 Pavia, Italy, Tel: +39-0382-987661; Fax: +39-0382422117; USA; E-mail: maurilio.sampaolesi@unipv.it

Received September 04, 2012; Accepted September 24, 2012; Published September 26, 2012

Citation: Ceccarelli G, Ronzoni F, Quattrocelli M, Galli D, Benedetti L, et al. (2012) Mononucleated Cells to Regenerate Skeletal Muscle Syncytial Tissues. J Stem Cell Res Ther S11:002. doi:10.4172/2157-7633.S11-002

Copyright: @ 2012 Chakkalakal JV, et al. This is an open-access article distributed under the terms of the Creative Commons Attribution License, which permits unrestricted use, distribution, and reproduction in any medium, provided the original author and source are credited. 
$(m d x / u t n r-)$ has been generated, showing a closer phenotype to DMD patients, including cardiomyopathy $[9,21]$.

For LMGD2 diseases, $\gamma, \alpha, \beta$, and $\delta$ sarcoglycan knock-out (KO) mice were generated $[22,23]$. These mice show chronic skeletal muscle degeneration and, in the case of $\gamma, \beta$, and $\delta$ sarcoglycan-KO mice also heart is affected, developing a dilated cardiomyopathy [23]. LGMD mice are considered a better animal model than $m d x$ mice for preclinical studies because of their lack of revertant fibres.

There are also canine models of DMD that exhibits similar clinical symptoms to human DMD [24]. Canine X-linked muscular dystrophy models include the golden retriever muscular dystrophy [25] dog and German shorthaired pointer. The canine models more accurately phenocopy the human disease than other animal models [26].

Facio-scapulo-humeral muscular dystrophy (FSHD) is a severe form of muscular dystrophy and it is the third most common human myopathy. The disease is characterized by a progressive degeneration of a highly selective set of muscle groups [27]. As its name suggests, muscles weakness regards facial mimic and shoulder girdle muscles. The FSHD derives for the interplay of complex genetic and epigenetic events [28]. In 95\% cases, the pathology is caused by the overexpression of the gene called FRG1 (FSHD region gene 1). Overexpression of FRG1 in mice causes a myopathy with some similarities to FSHD. For this reason, FSHD is the ideal candidate for the using of RNAi-mediated gene silencing therapeutic approaches [29].

\section{Multi- and Pluri-potent Stem Cells for Myogenic Commitment}

Stem cells are mononucleated cells able to self-renew and differentiate into diverse specialized cell types. We can divide them in two categories: pluripotent stem cells such as iPS (see below) and embryonic stem cells (ES), isolated from the inner cell mass of blastocysts, and multipotent stem cells, present in various adult tissues. While they are in principle to act as repair tissue system in adulthood, in a developing embryo they allow the generation of specialized tissues maintaining the normal turnover of regenerative organs, especially for blood, skin and intestine. Embryonic stem cells (ESCs) are considered the most promising source for cell therapy, but complex biological and ethical problems correlated with ESCs have hampered their use in favour of adult stem cell strategies [30]. In mammals, there are several stem cell types with varying myogenic potential that could be eventually used for therapeutic approaches, as discussed in the following paragraphs.

\section{Stem Cells from Bone Marrow, Adipose Tissue and Amniotic Fluid}

Among the cell types used in preclinical studies for the regeneration of muscle tissue, mesenchymal stem cells (MSCs) can be isolated from different tissues, such as adipose tissue, dental pulp, placenta, umbilical cord and fallopian tube [31-34]. However, an important question is whether MSCs from different sources are comparable in their differentiation potential in vivo or whether the stem cell niche of their origin influences their plasticity. It has been previously suggested that hMSCs from bone marrow and human circulating $\mathrm{AC}_{133^{+}}$stem cells, when co-cultured with mouse skeletal myoblasts, form myotubes by fusion and commit functionally in the myogenic environment [3537]. However, obtaining cells from bone marrow is not a very easy procedure and yields a low number of hMSCs.
A great impulse in the studies of MSCs in dystrophies was given by the multipotent adipose-derived stem cells (hASCs). hASCs are similar to MSCs, they maintain mesenchymal lineage and they are more easily available. hASCs can differentiate into skeletal muscle cells in vitro either in co-culture with skeletal myoblasts, or when cultured in medium supplemented with horse serum and/or under reduced serum conditions. In particular, spontaneous fusion of ASCs and subsequent myotube-like formation was observed in early culture passages at high cell density $[38,39]$.

Recently, it was described a population of mesenchymal progenitors, distinct from satellite cells, in the skeletal muscle. These progenitors have many similarities with hASCs, they do not generate myofibres spontaneously, but they enhance the rate of differentiation of primary myogenic progenitors, and they have adipogenic differentiation potential both in vitro and in vivo [40]. The interaction between muscle cells and these mesenchymal progenitors has a considerable impact on muscle homeostasis since adipogenesis is strongly inhibited by the presence of satellite cell-derived myofibres.

It has also been demonstrated that the transplantation of haematopoietic cell alone does not report any improvement in restoring dystrophin or other muscle genes in dystrophic mice [41]. In addition, the use of immunosuppressants in heterologous transplantation of hematopoietic stem cells (HSCs) may cause toxicity to many organs, such as kidney, liver, muscle and bone. However, an interesting study demonstrated an increased in the dystrophin gene in DMD dogs up to $7 \%$ of wild-type levels and it was maintained for at least 24 weeks, without any pharmacological immunosuppression [42].

Another promising source of stem cells for myogenic restoration is the amniotic fluid. In fact, human amniotic fluid stem (hAFS) cells is a novel class of stem cells that shares characteristics of both embryonic and adult stem cells and they have been regarded as promising candidate for cell therapy [43]. Many groups have confirmed that AFS cells have the potential to differentiate into hematopoietic, neurogenic, osteogenic, chondrogenic, adipogenic, renal, hepatic, and muscular lineages $[44,45]$. Although, regarding their biological properties and marker expression pattern, AFS cells appear to be more similar to embryonic stem (ES) cells than, for example, to trophoblast cells, the precise origin of AFS cells remains elusive. Many therapeutic approaches using AFS cells are currently under investigations and, recently, results demonstrated how AFS cells represent a powerful tool for regenerative medicine [46]. As regards muscle regeneration, De Coppi et al. [44] demonstrated that vein transplantation of mouse amniotic fluid stem cells enhances the muscle strength and improves the survival rate of dystrophic mice [47]. AFS cells integrate in the stem cell muscle compartment and they show a great capacity to regenerate muscle injuries as well as satellite cell pool.

\section{Muscle Myogenic-committed Stem Cells}

To restore muscles affected by Duchenne and Becker dystrophies several types of muscle-derived cell transplantation strategies have been tested in animals and in a few DMD patients [48]. Muscle precursor cells, known as myoblasts and derived from quiescent satellite cells, were one of the first cell types explored in pioneer transplantation studies, but intramuscular injections of myoblasts did not show great results, because of the rapid death of injected cells and the failure of the migration of injected myoblasts from the infusion site [49,50].

Nevertheless, satellite cells are still considered the major candidate 
for muscle regeneration in muscular dystrophies. It was demonstrated that a single satellite cell could reform new myofibres with the recovery of the physiological function of contraction. Initially quiescent satellite cells expressing Pax7 and Pax3 migrate to the site of damage, and start to up-regulate $M y o D$ and $M y f 5$, and become proliferative myoblasts.

Finally, Mrf4 and Myogenin positive myoblasts form multinucleated myofibres or fuse to damaged myofibres [51-54].

Recently, interesting studies revealed the presence of musclederived stem cells (MDSCs), as possible predecessor of satellite cells [55]. These cells, isolated from late pre-plating mononucleated muscle cells are not limited to the myogenic lineage; they can differentiate into other lineages (bone, cartilage, tendons) in vivo and in vitro. These cells present high-level proliferation, high self-renewal, immuneprivileged behaviour, and a superior capacity to regenerate skeletal muscle. In addition, MDSCs can be easily infected with viral vectors for gene therapy strategies, which is a very important attribute in the development of tissue engineering applications towards muscular dystrophies $[55,56]$. There are also muscle side population (SP) cells, which are being investigated as potential myogenic progenitors. They are associated with the muscle vascular system and are spontaneously committed towards the haematopoietic lineage [57]. In co-cultures with myoblasts, SP cells are able to form myotubes and, if injected intramuscularly into crushed tibialis of a scid immunodeficient mouse, can restore up to $1 \%$ of regenerating fibres [58].

In addition, in recent years, a new type of vessel-associated muscle-derived stem cells, termed mesoangioblasts (MABs), has been investigated as a potential therapy for muscular dystrophy. Mesoangioblasts isolated from murine embryonic dorsal aorta differentiate rapidly into tissues of mesodermal origin, including smooth, skeletal and cardiac muscle, and also into osteogenic, chondrogenic and adipogenic lineages $[59,60]$. MABs display high proliferation rate in vitro, without any tumour transformation potential. Incorporated into skeletal muscle fibres, they contribute to the satellite cell compartment and promote expression of muscle-specific proteins. In the environment of severe muscle damage in the $m d x / u t r n^{-/}$mouse, mesoangioblasts continue to proliferate and promote regeneration, migrate to adjacent damaged muscles and differentiate into multiple tissue types [59-61].

\section{iPS Cells}

In recent years, induced-pluripotent stem (iPS) cells have been used instem cell-based therapies for muscular and cardiac diseases. It has been demonstrated that mouse and human fibroblasts can be reprogrammed into an ESC-like state by introducing combinations of several transcription factors, including Oct-3/4, Sox2, c-Myc, and Klf4 $[62,63]$. The cells have been shown to exhibit ESC-like characteristics in terms of self-renewal, expression of ESC markers, and differentiation towards three germ layers in vitro and in vivo [64]. iPSCs are able to differentiate spontaneously into cardiomyocytes, providing a donor cell source to treat a mouse model of acute myocardial infarction and also having the interesting feature of reducing tumour formation after transplantation. iPSCs may bypass the ethical problems correlated with ESCs and their potentiality could represent a powerful tool for muscular regenerative therapy [65]. Nevertheless, the in vivo safety of iPSCs remains controversial [66]. In fact, Wang et.al, for example, demonstrated that tail-tip fibroblasts prepared from 14-month-old $m d x$ mice were highly proliferative and efficiently reprogrammed, and stable in culture, but fibroblasts isolated from muscle of $m d x$ mice at different ages showed lower proliferative activity and lower reprogramming efficiency, compared with those from younger $m d x$ mice [67]. Therefore, iPSCs generated from patients with Duchenne and Becker dystrophies represent a good source in terms of plasticity and life span, but further studies will be necessary to elucidate cellular and molecular mechanisms of iPSCs that could be the basis for the cell therapy of human disorders.

\section{Stem Cell Therapy with Multi- and Pluripotent Stem Cells}

Cell-based therapies have been largely considered a promising therapeutic tool for the treatment of muscular dystrophies and for the regeneration of a mature muscle tissue [5]. Satellite cells, the stem cell of muscle tissue, represent a good cell model for the treatment of dystrophies. In fact, $m d x$ irradiated mice transplanted intramuscularly with $\mathrm{Pax} 7^{+} \mathrm{CD} 34^{+} \mathrm{GFP}^{+}$satellite cells, demonstrated a good restoration of dystrophin expression in many skeletal fibres and a real contribution to the resident satellite compartment [68]. Nevertheless, satellite cells have a low migration capability and they show impaired engraftment potential when expanded in vitro. Besides, $w t$ myoblasts transplantation in dystrophic muscles restored dystrophin expression, but it has been observed a poor cell survival and a limited distribution of the transplanted cells $[68,69]$.

MDSCs and SP cells in co-culture with myoblasts, they can form myotubes in vitro and, if injected intramuscularly into crushed tibialis of a scid/bg immunodeficient mouse, can give rise to up to $1 \%$ of regenerating fibres [48]. Cell therapy with MDSCs and muscle side population (SP) cells demonstrated the re-establishment of dystrophin expression in the $m d x$ mouse more efficiently than myoblasts during an extended period [55-57].

Vessel-associated muscle-derived stem cells (MABs) represent another example of stem cells used in preclinical animal models of muscular dystrophy. In fact, as well as the application of MABs therapy on $m d x / u t r n^{-1}$ mice [68-70], Sampaolesi et al. [60] demonstrated the effectiveness of MABs in a canine model of muscular dystrophy. The intra-arterial delivery of wild-type canine mesoangioblasts in DMD Golden Retriever dogs produces an extensive recovery of dystrophin expression, normal muscle morphology and function. In addition, similar results have been achieved by human MABs transplantation into scid-mdx immunodeficient dystrophic mice [59]. It is very evident that MABs cell therapy shows long-term benefits in dystrophic animals, in terms of general motility restoration and whole muscle regeneration. Nevertheless, the problem of the use of steroids and immunosuppressant drugs remains critically for the use of those cells in heterologous cell therapies.

Other adult-derived stem cells have been isolated and characterized for the use in animal transplantation experiments, such as bone marrow-derived stem cells (BMSCs), adipose-derived stem cells (ASCs), hematopoietic stem cells (HSCs) and amniotic-fluid stem cells (AFSCs). After bone marrow transplantation in dystrophic mice, bone marrow-derived stem cells (BMSCs) are able to migrate and contribute to the formation of new $M y f 5^{+}$fibres [71]. In addition, it has been demonstrated that injections of hASCs into tibialis anterior of immunocompetent and immunosuppressed $m d x$ mice allowed the restoration of fused myofibres and, after 6 month from transplantation, chimaericmyofibres expressing human dystrophin appeared [38,39,72]. 
In fact, mesenchymal stem cells in general have a positive effect when interacting with the host muscle, but there are also evidences in the literature describing the immunosuppressive properties of MSCs $[40,73]$. Inflammatory infiltration is observed in the dystrophic muscles but little is known about the mechanisms involved in mesenchymal immunomodulation. Finally, the use of hematopoietic stem cells (HSCs) may cause toxicity to many organs, and their use is very restricted.

The interest of applying iPSCs technology to generate autologous cells for therapeutic purposes is a key challenge in future therapy. The iPS cells can be obtained through direct reprogramming of different human somatic cells to a pluripotent state with viral and/or non-viral methods [67]. There are several protocols to differentiate murine IP cells to myoblasts, such as a transfection with plasmid expressing myogenic factors. In particular, MABs reprogrammed to a pluripotent state (MAB-iPSCs) and subsequently transfected with Pax3 and Pax7 are capable to form myotubes in vitro more efficiently than fibroblastderived iPS cells (f-IPSCs) [74]. Quattrocelli et al. [74] concluded that MAB-iPSCs contain an intrinsic myogenic cell memory compared to iPSCs obtained from fibroblasts (f-iPSCs). Another important study focused on the effectiveness of human ES/iPS cells reprogrammed from fibroblasts to repair dystrophic muscle. In fact, the intramuscular transplantation of TA muscles with ES- or iPSCs transfected with Pax7 showed not only a restoring in the expression of dystrophin gene in $m d x$ mice, but also showed an improving in the strength generation of engrafted muscles [75]. The future goal for the use of iPSCs in cell therapy is to discover non-genetic methods of delivering factors to generate myogenic progenitors. These methods could include the use of safer transient vectors, recombinant proteins, or the use of synthetic modified mRNAs.

As regards, human artificial chromosome (HAC) vector has many advantages in gene therapy, including the ability to carry large gene inserts including the regulatory elements. It has been demonstrated that a HAC vector containing the entire dystrophin gene (DYS-HAC) is able to correct mutation and deletion of dystrophin in iPSCsderived from $m d x$ mice [76]. In addition, an improvement of the dystrophic phenotype in the $m d x$ mouse model was achieved by a combination of HAC-mediated gene replacement MABs transplantation protocols [77]. Corrected mesoangioblasts showed an increase in the reestablishment of dystrophin-positive muscle fibres and in the pool of muscle satellite cells in $m d x$ mice. Therefore, HAC-mediated gene transfer shows positive effects in preclinical model of DMD and could offer potentials for future clinical translation in clinical therapy (Figure $1)$.

\section{New Insights from Direct Reprogramming and Epigenetic Signalling (miRNAs and RNAi)}

The mutation of Dystrophin gene in DMD patients is associated with a dysfunction of several proteins correlated with the dystrophin gene, such as $\alpha, \beta, \gamma$, and $\delta$ sarcoglycans, sarcospan, and other proteins, such as $\alpha$-dystrobrevin, $\alpha 1, \beta 1, \beta 2, \gamma 1, \gamma 2$, calveolin, growth factor receptor-bound protein-2(Grb2), and neuronal Nitric Oxide Synthase ( $n N O S$ ) [78]. It has been found that mRNA levels are altered in the human DMD pathology, and in this background an important role in regulating several biological responses in muscle cells, ranging from proliferation, differentiation and modification of mRNA was given by the microRNAs (miRNAs) [79,80]. miRNAs are a class of posttranscriptional regulators and they are short $\sim 22$ nucleotide RNA

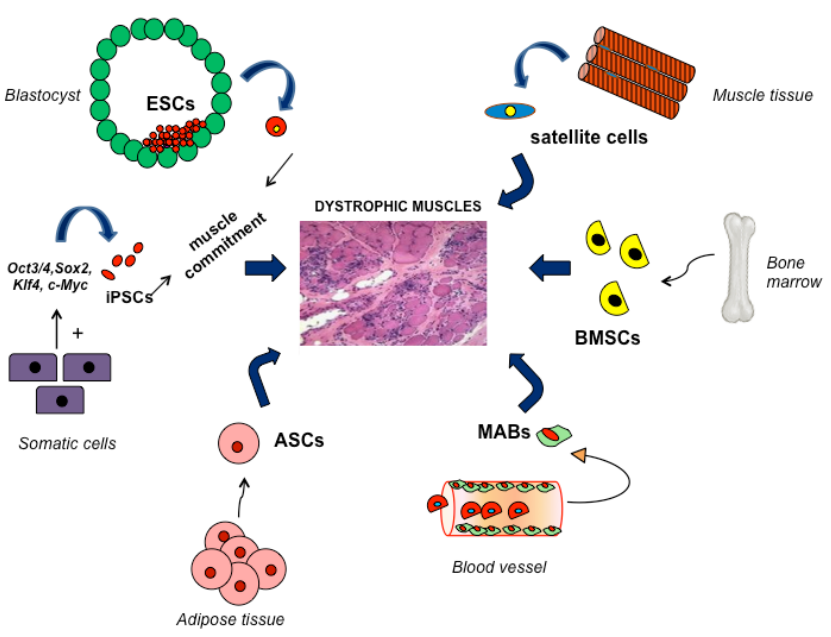

Figure 1: Stem cell types for the treatment of skeletal muscle degeneration. ESCs, embryonic stem cells; iPSCs, induced pluripotent stem cells; BMSCs, bone marrow-derived stem cells; MABs, mesoangioblasts; ASCs, adiposederived stem cells.

sequences that bind to complementary sequences in the 3' UTR of multiple target mRNAs, usually resulting in their silencing. It has been shown that myosin genes [81] encode miRNAs controlling muscle performance. Hence, all the identified muscle miRNAs indirectly promote myogenesis, rather than acting directly on key regulatory factors for muscle differentiation. Crippa et al. [82] demonstrated that among the miRNAs known that regulate skeletal myogenesis, only miR669a and miR669q directly inhibit the MyoD 3' untranslated region (UTR) and, consequently, skeletal myogenesis $[82,83]$. miR669a and miR669 $q$ are the first identified miRNAs that act upstream of MyoD, thus indirectly regulating all MyoD targets. The novelty of this study is that the dysregulation of both these miRNAs is necessary to activate skeletal myogenesis in $\beta$-sarcoglycan know-out cardiac progenitors. On the contrary, in $w t$ cardiac progenitors miR669 family is capable of repressing skeletal myogenesis by inhibiting $M y o D$ expression [82]. So far, the understanding of the regulatory network of the miRNAs in dystrophic diseases and their role in the activation of satellite cells in a damage muscle represents an important starting point to be focused on future research and therapies.

In addition, another important approach to display new therapy for muscular dystrophies is the RNAi-based technique [84]. RNAi is a process within living cells that moderates the activity of their gene targets; it is an RNA-dependent gene silencing process, that cells use to defend themselves against parasitic genes, viruses and transposons, but also in directing development as well as gene expression in general [84]. Bortolanza et al. [29] explored the therapeutic potentials of RNAi gene silencing. In fact, the FSHD is caused by the over-expression of the FRG1 gene, and, therefore, its inhibition would be expected to lead to a therapeutic benefit in FSHD. The group demonstrated that injected FSHD-/- mice with a viral vector containing AAV6-sh1 FRG1 doses displayed a reduction in FRG1 expression in all the analyzed muscles and a positive general physiological recovery, without any evidence of toxicity in any of the treated mice. This work opens the doors to future investigations on RNAi-based techniques and their clinical applications and treatment for particular muscular dystrophies in which aberrant up-regulation of specific genes is involved. This new 
therapy allowed significant improvement of disease in $\mathrm{FSHD}^{-/}$mice and could potentially be translated to human patients to develop new therapies.

\section{Conclusions and Perspectives}

Skeletal muscle tissue offers several advantages to exploit and explore stem cell therapy approaches. It is a multinucleated tissue that efficiently regenerates after injury by a very defined biological program characterized by progenitor cell proliferation, cell fusion and differentiation. Nevertheless, this fantastic regenerative process cannot successfully counteract skeletal muscle chronic degeneration. Several animal models were generated or discovered in animal colonies mimicking the human diseases. In the early 60 ' Mauro described for the first time satellite cells, which have been hypothesized as remaining embryonic myoblasts from the developing somites [85]. Several following studies have demonstrated that progenitor cells from the dermomyotome give rise to satellite cells, although it still questionable if those cells are the unique precursors of adult satellite cells. Skeletal muscle regeneration is possible for the ability of satellite cells to react to appropriate stimuli, in which stem cell niche, growth factors and many regulatory molecules, including miRNAs play a major role. After an injury, HGF and IGF activate and stimulate satellite cell proliferation, while specific miRNAs and TGF- $\beta 1$ negatively influenced this process. In addition, besides satellite cells, a wide range of resident stem cells, seem to be primary involved in the process.

In muscular dystrophies the regenerative machinery is altered and exhausted by degeneration and regeneration cycles. For possible cell- based therapeutic approaches satellite cells are unsuitable since they are not able to cross endothelial barrier, and more than $95 \%$ of injected satellite cells die the first days after injection. For these limitations it appears clear that other stem cells, including the MDSCs, MABs, MSCs, ASCs, AFSCs and iPS cells, may turn out to be more suitable for the treatment of skeletal muscle degenerations. Ongoing research will possibly reveal the stem cell niche components of skeletal muscles, with the ultimate goal to obtain biological substrates and molecules to better maintain stem cells in culture. The possibility to generate myogenic stem cells from patient somatic cells is also an attractive strategy to bypass immunological issues. In addition, further elucidation on epigenetic memory could help in the choice of cell sources to be reprogrammed. However, it is largely unknown whether those newly generated stem cells are able to home to the satellite cell niche, prolonging the regeneration capacity of newly formed myofibres. Finally, several recent studies reveal the possibility to use miRNA technology to guarantee a better myogenic commitment of stem cells. Several clinical trials have been already started, involving myoblast or perycyte injection from HLA-matched donors. Unfortunately, the current stringent regulatory constraints will prolong significantly the clinical translation of novel approaches, including miRNA and iPS cell technologies for muscular dystrophies. In addition, any stem cell injected into a patient has to be produced under stringent and very expensive GMP (good manufacture practice) conditions. In the nearly future, in order to accelerate translational studies it is critical to promote and support multidisciplinary research networks, involving industrial and academic laboratories (Table 1).

\begin{tabular}{|c|c|c|c|}
\hline Stem cell & Origin & Characteristics & Preclinical/clinical studies \\
\hline ES cells & Inner cell mass of the blastocysts & $\begin{array}{l}\text { pluripotent stem cells } \\
\text { biological and ethical problems } \\
\text { teratoma formation } \\
\text { graft versus-host disease }\end{array}$ & on mdx mice [30] \\
\hline ¡PS cells & $\begin{array}{l}\text { Reprogrammed mouse or human somatic } \\
\text { cells }\end{array}$ & $\begin{array}{l}\text { pluripotent stem cells } \\
\text { no ethical problems } \\
\text { autologous transplantation possible } \\
\text { teratoma formation }\end{array}$ & $\begin{array}{l}\text { on mdx mice,alphaSG-null and } \\
\text { alphaSG-null/Scid/bg }[67,73,74]\end{array}$ \\
\hline Amniotic fluid stem cells & Amniotic fluid & $\begin{array}{l}\text { multipotent stem cells } \\
\text { no ethical problems } \\
\text { easy to isolate and expand in culture }\end{array}$ & dystrophic mice [44-47] \\
\hline Muscle -SP Cells & Muscle tissue & $\begin{array}{l}\text { multipotent cells } \\
\text { high proliferation }\end{array}$ & $\begin{array}{l}\text { Scid/bg immunodeficient mice } \\
{[48,57,58]}\end{array}$ \\
\hline Satellite cells & Muscle fibres, under the basal lamina & $\begin{array}{l}\text { high self-renewal } \\
\text { high capacity to generate skeletal muscle } \\
\text { limited engraftment and migration }\end{array}$ & $\begin{array}{l}\text { Nude mice, pigs, trial on humans } \\
{[51-54] .}\end{array}$ \\
\hline Mesoangioblast cells (MABs) & Muscle blood vessels, pericyte & $\begin{array}{l}\text { high proliferation in vitro } \\
\text { no tumor transformation } \\
\text { able to pass the endothelial layer }\end{array}$ & $\begin{array}{l}\text { alphaSG-null, mdx/scid mice, } \\
\text { GRMD dogs [59-61]; phase I/II } \\
\text { clinical trial ongoing. }\end{array}$ \\
\hline Bone marrow stromal cells (BMSCs) & $\begin{array}{l}\text { Bone marrow and also from different } \\
\text { tissues (adipose, tendon, dental pulp, } \\
\text { placenta) }\end{array}$ & $\begin{array}{l}\text { multipotent stem cells } \\
\text { easy to isolate and expand in culture } \\
\text { immunomodulatory properties } \\
\text { anti-inflammatory properties } \\
\text { low engraftment }\end{array}$ & $\begin{array}{l}\text { mdx mice [56-58] } \\
\text { tissue engineering applications } \\
\text { (biomaterials, bioreactors, bone } \\
\text { implants) }\end{array}$ \\
\hline Adipose-derived stem cells (ASCs) & Adipose tissue & $\begin{array}{l}\text { very easy to isolate and } \\
\text { multipotent cells } \\
\text { high proliferation in vitro } \\
\text { immunosuppressive properties }\end{array}$ & $\begin{array}{l}\text { mdx mice, small-scale studies on } \\
\text { tissue engineering, as BMSCs (bone } \\
\text { implants, biomaterials) } \\
{[38,39,71]}\end{array}$ \\
\hline
\end{tabular}

Table 1: Origin and characteristics of stem cells involved in muscle regeneration. 
Citation: Ceccarelli G, Ronzoni F, Quattrocelli M, Galli D, Benedetti L, et al. (2012) Mononucleated Cells to Regenerate Skeletal Muscle Syncytial Tissues. J Stem Cell Res Ther S11:002. doi:10.4172/2157-7633.S11-002

Page 6 of 8

\section{Acknowledgment}

This work was supported in part by FWO- Odysseus Program n. G.0907.08; Research Council of the University of Leuven n. OT/09/053 and GOA11/012 CARE-MI n.242038 FP7-EC grant; FWO n. G.0606.12; Project Financiering 10/019; the Italian Ministry of University and Scientific Research grant n. PRIN 2008RFNT8T 003 and CARIPLO 2008-2005. We are grateful to Catherine Verfaillie for continuous support, Danny Huylebroeck, and An Zwijsen for helpfu discussion; we thank Luigi Vercesi for the professional secretarial service and Paolo Luban for a kind donation.

\section{References}

1. Nigro V, Aurino S, Piluso G (2011) Limb girdle muscular dystrophies: update on genetic diagnosis and therapeutic approaches. Curr Opin Neurol 24: 429-436.

2. Sparks SE, Escolar DM (2011) Congenital muscular dystrophies. Handb Clin Neurol 101: 47-79.

3. Emery AE (2002) The muscular dystrophies. Lancet 359: 687-695

4. Cassano M, Quattrocelli M, Crippa S, Perini I, Ronzoni F, et al. (2009) Cellular mechanisms and local progenitor activation to regulate skeletal muscle mass. J Muscle Res Cell Motil 30: 243-253.

5. Quattrocelli M, Cassano M, Crippa S, Perini I, Sampaolesi M (2010) Cell therapy strategies and improvements for muscular dystrophy. Cell Death Differ 17: $1222-1229$.

6. Bogdanovich S, Perkins KJ, Krag TO, Khurana TS (2004) Therapeutics for Duchenne muscular dystrophy: current approaches and future directions. J Mol Med (Berl) 82: 102-115.

7. Cossu G, Sampaolesi M (2007) New therapies for Duchenne muscular dystrophy: challenges, prospects and clinical trials. Trends Mol Med 13: 520526

8. Nadaj-Pakleza A, Lusakowska A, Sułek-Piątkowska A, Krysa W, Rajkiewicz $\mathrm{M}$, et al. (2011) Muscle pathology in myotonic dystrophy: light and electron microscopic investigation in eighteen patients. Folia Morphol (Warsz) 70: 121129.

9. Hirst RC, McCullagh KJ, Davies KE (2005) Utrophinupregulation in Duchenne muscular dystrophy. Acta Myol 24: 209-216.

10. Onofre-Oliveira PC, Santos AL, Martins PM, Ayub-Guerrieri D, Vainzof M (2012) Differential expression of genes involved in the degeneration and regeneration pathways in mouse models for muscular dystrophies. Neuromolecular Med 14: 74-83.

11. Hoffman EP, Brown RH Jr, Kunkel LM (1987) Dystrophin: the protein product of the Duchenne muscular dystrophy locus. Cell 51: 919-928.

12. Wang Q, Yang X, Yan Y, Song N, Lin C, et al. (2011) Duchenne or Becker muscular dystrophy: a clinical, genetic and immunohistochemical study in China. Neurol India 59: 797-802.

13. Laing NG, Davis MR, Bayley K, Fletcher S, Wilton SD (2011) Molecular diagnosis of duchenne muscular dystrophy: past, present and future in relation to implementing therapies. Clin Biochem Rev 32: 129-134.

14. Ferreira AF, Carvalho MS, Resende MB, Wakamatsu A, Reed UC, et al. (2011) Phenotypic and immunohistochemical characterization of sarcoglycanopathies. Clinics (Sao Paulo) 66: 1713-1719.

15. Cassano M, Dellavalle A, Tedesco FS, Quattrocelli M, Crippa S, et al. (2011) Alpha sarcoglycan is required for FGF-dependent myogenic progenitor cell proliferation in vitro and in vivo. Development 138: 4523-4533.

16. Allamand V, Campbell KP (2000) Animal models for muscular dystrophy: valuable tools for the development of therapies. Hum Mol Genet 9: 2459-2467.

17. Turk R, Sterrenburg E, de Meijer EJ, van Ommen GJ, den Dunnen JT, et al (2005) Muscle regeneration in dystrophin-deficient $\mathrm{mdx}$ mice studied by gene expression profiling. BMC Genomics 6: 98 .

18. Lu QL, Mann CJ, Lou F, Bou-Gharios G, Morris GE, et al. (2003) Functiona amounts of dystrophin produced by skipping the mutated exon in the $\mathrm{mdx}$ dystrophic mouse. Nat Med 9: 1009-1014.

19. Pastoret C, Sebille A (1995) mdx mice show progressive weakness and muscle deterioration with age. J Neurol Sci 129: 97-105.

20. DiMario JX, Uzman A, Strohman RC (1991) Fiber regeneration is not persistent in dystrophic (MDX) mouse skeletal muscle. Dev Biol 148: 314-321.

21. Weir AP, Burton EA, Harrod G, Davies KE (2002) A- and B-utrophin have different expression patterns and are differentially up-regulated in mdx muscle. J Biol Chem 277: 45285-45290.

22. Duclos F, Straub V, Moore SA, Venzke DP, Hrstka RF, et al. (1998) Progressive muscular dystrophy in alpha-sarcoglycan-deficient mice. J Cell Biol 142: 1461 1471.

23. Durbeej M, Cohn RD, Hrstka RF, Moore SA, Allamand V, et al. (2000) Disruption of the beta-sarcoglycan gene reveals pathogenetic complexity of limb-girdle muscular dystrophy type 2E. Mol Cell 5: 141-151.

24. Kornegay JN, Tuler SM, Miller DM, Levesque DC (1988) Muscular dystrophy in a litter of golden retriever dogs. Muscle Nerve 11: 1056-1064.

25. Kornegay JN, Bogan JR, Bogan DJ, Childers MK, Grange RW (2011) Golden retriever muscular dystrophy (GRMD): Developing and maintaining a colony and physiological functional measurements. Methods Mol Biol 709: 105-123.

26. Ambrósio CE, Fadel L, Gaiad TP, Martins DS, Araújo KP, et al. (2009) Identification of three distinguishable phenotypes in golden retriever muscular dystrophy. Genet Mol Res 8: 389-396.

27. Cabianca DS, Gabellini D (2010) The cell biology of disease: FSHD: copy number variations on the theme of muscular dystrophy. J Cell Biol 191: 1049 1060

28. Statland JM, Tawil R (2011) Facioscapulohumeral muscular dystrophy: molecular pathological advances and future directions. Curr Opin Neurol 24 423-428.

29. Bortolanza S, Nonis A, Sanvito F, Maciotta S, Sitia G, et al. (2011) AAV6mediated systemic shRNA delivery reverses disease in a mouse model of facioscapulohumeral muscular dystrophy. Mol Ther 19: 2055-2064.

30. Salani S, Donadoni C, Rizzo F, Bresolin N, Comi GP, et al. (2012) Generation of skeletal muscle cells from embryonic and induced pluripotent stem cells as an in vitro model and for therapy of muscular dystrophies. J Cell Mol Med 16 : 1353-1364.

31. Saulnier N, Lattanzi W, Puglisi MA, Pani G, Barba M, et al. (2009) Mesenchymal stromal cells multipotency and plasticity: induction toward the hepatic lineage. Eur Rev Med Pharmacol Sci 1: 71-78.

32. Beyth S, Schroeder J, Liebergall M (2011) Stem cells in bone diseases: current clinical practice. Br Med Bull 99: 199-210.

33. Dezawa M, Ishikawa H, Itokazu Y, Yoshihara T, Hoshino M, et al. (2005) Bone marrow stromal cells generate muscle cells and repair muscle degeneration. Science 309: 314-317.

34. Bianco P, Robey PG, Simmons PJ (2008) Mesenchymal stem cells: revisiting history, concepts, and assays. Cell Stem Cell 2: 313-319.

35. Torrente Y, Belicchi M, Sampaolesi M, Pisati F, Meregalli M, et al. (2004) Human circulating AC133(+) stem cells restore dystrophin expression and ameliorate function in dystrophic skeletal muscle. J Clin Invest 114: 182-195.

36. Gonçalves MA, Holkers M, Cudré-Mauroux C, van Nierop GP, Knaän-Shanzer $S$, et al. (2006) Transduction of myogenic cells by retargeted dual high-capacity hybrid viral vectors: robust dystrophin synthesis in duchenne muscular dystrophy muscle cells. Mol Ther 13: 976-986.

37. Schulze M, Belema-Bedada F, Technau A, Braun T (2005) Mesenchymal stem cells are recruited to striated muscle by NFAT/IL-4-mediated cell fusion. Genes Dev 19: 1787-1798.

38. Vieira NM, Zucconi E, Bueno CR Jr, Secco M, Suzuki MF, et al. (2010) Human multipotent mesenchymal stromal cells from distinct sources show different in vivo potential to differentiate into muscle cells when injected in dystrophic mice. Stem Cell Rev 6: 560-566.

39. Di Rocco G, lachininoto MG, Tritarelli A, Straino S, Zacheo A, et al. (2006) Myogenic potential of adipose-tissue-derived cells. J Cell Sci 119: 2945-2952.

40. De Miguel MP, Fuentes-Julián S, Blázquez-Martínez A, Pascual CY, Aller 
Citation: Ceccarelli G, Ronzoni F, Quattrocelli M, Galli D, Benedetti L, et al. (2012) Mononucleated Cells to Regenerate Skeletal Muscle Syncytial Tissues. J Stem Cell Res Ther S11:002. doi:10.4172/2157-7633.S11-002

Page 7 of 8

MA, et al. (2012) Immunosuppressive properties of mesenchymal stem cells: advances and applications. Curr Mol Med 12: 574-591.

41. Uezumi A, Ito T, Morikawa D, Shimizu N, Yoneda T, et al. (2011) Fibrosis and adipogenesis originate from a common mesenchymal progenitor in skeletal muscle. J Cell Sci 124: 3654-3664.

42. Parker MH, Kuhr C, Tapscott SJ, Storb R (2008) Hematopoietic cell transplantation provides an immune-tolerant platform for myoblast transplantation in dystrophic dogs. Mol Ther 16: 1340-1346.

43. Rosner M, Schipany K, Shanmugasundaram B, Lubec G, Hengstschläger M (2012) Amniotic fluid stem cells: future perspectives. Stem Cells Int 2012: 741810.

44. De Coppi P, Bartsch G Jr, Siddiqui MM, Xu T, Santos CC, et al. (2007) Isolation of amniotic stem cell lines with potential for therapy. Nat Biotechnol 25: $100-$ 106.

45. Orciani M, Emanuelli M, Martino C, Pugnaloni A, Tranquilli AL, et al. (2008) Potential role of culture mediums for successful isolation and neuronal differentiation of amniotic fluid stem cells. Int J Immunopathol Pharmacol 21: 595-602.

46. Kolambkar YM, Peister A, Soker S, Atala A, Guldberg RE (2007) Chondrogenic differentiation of amniotic fluid-derived stem cells. J Mol Histol 38: 405-413.

47. Piccoli M, Franzin C, Bertin E, Urbani L, Blaauw B, et al. (2012) Amniotic Fluid Stem Cells Restore the Muscle Cell Niche in a HSA-Cre, Smn(F7/F7) Mouse Model. Stem Cells 30: 1675-1684.

48. Cossu G, Sampaolesi M (2004) New therapies for muscular dystrophy: cautious optimism. Trends Mol Med 10: 516-520.

49. Negroni E, Vallese D, Vilquin JT, Butler-Browne G, Mouly V, et al. (2011) Current advances in cell therapy strategies for muscular dystrophies. Expert Opin Biol Ther 11: 157-176

50. Sacco A, Doyonnas R, Kraft P, Vitorovic S, Blau HM (2008) Self-renewal and expansion of single transplanted muscle stem cells. Nature 456: 502-506.

51. Laguens $R$ (1963) Satellite cells of skeletal muscle fibers in human progressive muscular dystrophy. Virchows Arch Pathol Anat Physiol Klin Med 336: 564-569.

52. Cossu G, Biressi S (2005) Satellite cells, myoblasts and other occasional myogenic progenitors: possible origin, phenotypic features and role in muscle regeneration. Semin Cell Dev Biol 16: 623-631.

53. Meng J, Adkin CF, Xu SW, Muntoni F, Morgan JE (2011) Contribution of human muscle-derived cells to skeletal muscle regeneration in dystrophic host mice. PLoS One 6: e17454.

54. Zammit PS (2008) All muscle satellite cells are equal, but are some more equal than others? J Cell Sci. 121: 2975-2982.

55. Usas A, Mačiulaitis J, Mačiulaitis R, Jakubonienè N, Milašius A, et al. (2011) Skeletal muscle-derived stem cells: implications for cell-mediated therapies. Medicina (Kaunas) 47: 469-479

56. Usas A, Huard J (2007) Muscle-derived stem cells for tissue engineering and regenerative therapy. Biomaterials 28: 5401-5406.

57. Asakura A, Seale P, Girgis-Gabardo A, Rudnicki MA (2002) Myogenic specification of side population cells in skeletal muscle. J Cell Biol 159: 123134

58. Bachrach E, Perez AL, Choi YH, Illigens BM, Jun SJ, et al. (2006) Muscle engraftment of myogenic progenitor cells following intraarterial transplantation. Muscle Nerve 34: 44-52.

59. Sampaolesi M, Torrente Y, Innocenzi A, Tonlorenzi R, D'Antona G, et al. (2003) Cell therapy of alpha-sarcoglycan null dystrophic mice through intra-arterial delivery of mesoangioblasts. Science 301: 487-492.

60. Sampaolesi M, Blot S, D’Antona G, Granger N, Tonlorenzi R, et al. (2006) Mesoangioblast stem cells ameliorate muscle function in dystrophic dogs. Nature 444: 574-579.

61. Minasi MG, Riminucci M, De Angelis L, Borello U, Berarducci B, et al. (2002) The meso-angioblast: a multipotent, self-renewing cell that originates from the dorsal aorta and differentiates into most mesodermal tissues. Development 129: $2773-2783$

62. Takahashi K, Yamanaka S (2006) Induction of pluripotent stem cells from mouse embryonic and adult fibroblast cultures by defined factors. Cell 126 663-676.

63. Wernig M, Meissner A, Foreman R, Brambrink T, Ku M, et al. (2007) In vitro reprogramming of fibroblasts into a pluripotent ES-cell-like state. Nature 448 318-324.

64. Das AK, Pal R (2010) Induced pluripotent stem cells (iPSCs): the emergence of a new champion in stem cell technology-driven biomedical applications. J Tissue Eng Regen Med 4: 413-421.

65. Nakagawa M, Koyanagi M, Tanabe K, Takahashi K, Ichisaka T, et al. (2008) Generation of induced pluripotent stem cells without Myc from mouse and human fibroblasts. Nat Biotechnol 26: 101-106.

66. Park IH, Arora N, Huo H, Maherali N, Ahfeldt T, et al. (2008) Disease-specific induced pluripotent stem cells. Cell 134: 877-886.

67. Wang B, Miyagoe-Suzuki Y, Yada E, Ito N, Nishiyama T, et al. (2011) Reprogramming efficiency and quality of induced Pluripotent Stem Cells (iPSCs) generated from muscle-derived fibroblasts of $\mathrm{mdx}$ mice at different ages. PLoS Curr 3: RRN1274.

68. Bentzinger CF, Wang YX, von Maltzahn J, Rudnicki MA (2012) The emerging biology of muscle stem cells: Implications for cell-based therapies. Bioessays [Epub ahead of print]

69. Galvez BG, Sampaolesi M, Brunelli S, Covarello D, Gavina M, et al. (2006) Complete repair of dystrophic skeletal muscle by mesoangioblasts with enhanced migration ability. J Cell Biol 174: 231-243.

70. Berry SE, Liu J, Chaney EJ, Kaufman SJ (2007) Multipotential mesoangioblast stem cell therapy in the mdx/utrn-/- mouse model for Duchenne muscular dystrophy. Regen Med 2: 275-288.

71. Bittner RE, Schöfer C, Weipoltshammer K, Ivanova S, Streubel B, et al. (1999) Recruitment of bone-marrow-derived cells by skeletal and cardiac muscle in adult dystrophic mdx mice. Anat Embryol (Berl) 199: 391-396.

72. Vieira NM, Bueno CR Jr, Brandalise V, Moraes LV, Zucconi E, et al. (2008) SJL dystrophic mice express a significant amount of human muscle proteins following systemic delivery of human adipose-derived stromal cells without immunosuppression. Stem Cells 26: 2391-2398.

73. Uccelli A, Moretta L, Pistoia V (2008) Mesenchymal stem cells in health and disease. Nat Rev Immunol 8: 726-736.

74. Quattrocelli M, Palazzolo G, Floris G, Schöffski P, Anastasia L, et al. (2011) Intrinsic cell memory reinforces myogenic commitment of pericyte-derived iPSCs. J Pathol 223: 593-603.

75. Darabi R, Arpke RW, Irion S, Dimos JT, Grskovic M, et al. (2012) Human ES- and iPS-derived myogenic progenitors restore dystrophin and improve contractility upon transplantation in dystrophic mice. Cell Stem Cell 10: 610 619

76. Kazuki Y, Hiratsuka M, Takiguchi M, Osaki M, Kajitani N, et al. (2010) Complete genetic correction of ips cells from Duchenne muscular dystrophy. Mol Ther 18: 386-393.

77. Tedesco FS, Hoshiya H, D'Antona G, Gerli MF, Messina G, et al. (2011) Stem cell-mediated transfer of a human artificial chromosome ameliorates muscular dystrophy. Sci Transl Med 3: 96ra78.

78. Buono R, Vantaggiato C, Pisa V, Azzoni E, Bassi MT, et al. (2012) Nitric oxide sustains long-term skeletal muscle regeneration by regulating fate of satellite cells via signaling pathways requiring Vangl2 and cyclic GMP. Stem Cells 30 197-209.

79. Eisenberg I, Eran A, Nishino I, Moggio M, Lamperti C, et al. (2007) Distinctive patterns of microRNA expression in primary muscular disorders. Proc Nat Acad Sci U S A 104: 17016-17021.

80. Greco S, De Simone M, Colussi C, Zaccagnini G, Fasanaro P, et al. (2009) Common micro-RNA signature in skeletal muscle damage and regeneration 
Citation: Ceccarelli G, Ronzoni F, Quattrocelli M, Galli D, Benedetti L, et al. (2012) Mononucleated Cells to Regenerate Skeletal Muscle Syncytial Tissues. J Stem Cell Res Ther S11:002. doi:10.4172/2157-7633.S11-002

Page 8 of 8

induced by Duchenne muscular dystrophy and acute ischemia. FASEB $\mathrm{J} 23$ : $3335-3346$.

81. van Rooij E, Quiat D, Johnson BA, Sutherland LB, Qi X, et al. (2009) A family of microRNAs encoded by myosin genes governs myosin expression and muscle performance. Dev Cell 17: 662-673.

82. Crippa S, Cassano M, Messina G, Galli D, Galvez BG, et al. (2011) miR669a and miR669q prevent skeletal muscle differentiation in postnatal cardiac progenitors. J Cell Biol 193: 1197-1212.
83. Crippa S, Cassano M, Sampaolesi M (2012) Role of miRNAs in muscle stem cell biology: proliferation, differentiation and death. Curr Pharm Des 18: 17181729.

84. Seyhan AA (2011) RNAi: a potential new class of therapeutic for human genetic disease. Hum Genet 130: 583-605.

85. Mauro A (1961) Satellite cell of skeletal muscle fibers. J Biophys Biochem Cyto 9: 493-495. 